phy performed 1 month after surgery demonstrated a morphologically and functionally normal autograft.

Four years later, a routine follow-up echocardiography was performed in the clinically asymptomatic patient and revealed good left ventricular function with an ejection fraction of $65 \%$. Although no recurrence of aortic stenosis was detectable, a seconddegree aortic regurgitation (Figure 1) was evident in color Doppler echocardiography. The patient denied any symptoms, despite her physically demanding profession.

\section{Discussion}

Donald Ross ${ }^{1}$ introduced the use of the pulmonary autograft for aortic valve replacement in 1967. This technique allows the replacement of a diseased aortic valve with the autologous PV. Thus, systemic anticoagulation is circumvented, and the risk of thromboembolism or cerebral bleeding is negligible. In comparison with all other valve substitutes, the free-root technique shows the best hemodynamic outcome and consequently is the most frequently used approach. ${ }^{4}$ However, the normally tricuspid PV must be of regular anatomy and function. To our knowledge the use of a quadricuspid pulmonary autograft has not been described before. The early postoperative result with the quadricuspid autograft was promising. However, the development of autograft regurgitation of second degree (echocardiographic guidelines) as early as 4 years after surgical treatment identifies quadricuspid autografts as potentially problematic for this procedure. Preoperative echocardiographic evaluation of PV function and morphology are therefore mandatory.

\section{References}

1. Ross DN. Replacement of aortic and mitral valves with a pulmonary autograft. Lancet. 1967;2:956-8.

2. Shimada K, Yokoi A, Kitagawa T, Asuwa N, Ishii T. A supernumerary cusp in the human pulmonary valve. Surg Radiol Anat. 1990;12:69-71.

3. Berdajs D, Lajos P, Zund G, Turina M. The quadricuspid pulmonary valve: its importance in the Ross procedure. J Thorac Cardiovasc Surg. 2003;125:198-9.

4. Kouchoukos NT, Masetti P, Nickerson NJ, Castner CF, Shannon WD, Davila-Roman VG. The Ross procedure: long-term clinical and echocardiographic follow-up. Ann Thorac Surg. 2004;78:773-81.

\title{
Aortic root replacement in a patient with pulmonary dysfunction caused by severe chest deformity associated with Marfan syndrome
}

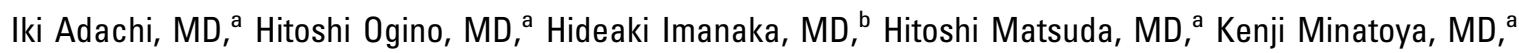
and Hiroaki Sasaki, MD, ${ }^{a}$ Osaka, Japan

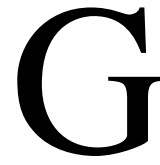
reat advances in respiratory management have recently widened the indication for cardiovascular surgery for patients with pulmonary dysfunction. We describe a patient with an extremely low vital capacity caused by severe chest deformity who tolerated aortic root replacement as a result of adequate respiratory management, including bilevel positive airway pressure (BiPAP) ventilation.

\section{Clinical Summary}

A 39-year-old man with Marfan syndrome was scheduled to undergo aortic root replacement for annuloaortic ectasia and aortic insufficiency. He had been receiving home oxygen therapy for 10 years and nocturnal use of nasal continuous positive airway pres-

From the Department of Cardiovascular Surgery ${ }^{\mathrm{a}}$ and the Intensive Care Unit, ${ }^{\text {b }}$ National Cardiovascular Center, Osaka, Japan.

Received for publication Jan 3, 2005; revisions received Jan 15, 2005; accepted for publication Feb 8, 2005.

Address for reprints: Hitoshi Ogino, MD, 5-7-1 Fujishiro-dai, Suita, Osaka 565-8565, Japan (E-mail: hogino@hsp.ncvc.go.jp).

J Thorac Cardiovasc Surg 2005;130:213-5

$0022-5223 / \$ 30.00$

Copyright $\odot 2005$ by The American Association for Thoracic Surgery

doi:10.1016/j.jtcvs.2005.02.031 sure ventilation for 1 year because of frequent episodes of respiratory failure.

On admission, he showed respiratory distress at grade IV of the Hugh-Jones classification. Spirometry showed a severe restrictive pattern: vital capacity of $1080 \mathrm{~mL}$ ( $28 \%$ of predicted value) and forced expiratory volume in 1 second of $890 \mathrm{~mL}$. Arterial blood gases (ABGs) under $1 \mathrm{~L}$ of oxygen inhalation revealed metabolically compensated hypercapnia: $\mathrm{pH}, 7.41 ; \mathrm{PaCO}_{2}, 60.8 \mathrm{~mm} \mathrm{Hg}$; $\mathrm{PaO}_{2}, 80.4 \mathrm{~mm} \mathrm{Hg}$; base excess, $10.9 \mathrm{mmol} / \mathrm{L}$. Chest radiography showed cardiomegaly with mild lung congestion and severe scoliosis (Figure 1). Computed tomographic (CT) scans revealed the dilated aortic root (62 $\mathrm{mm}$ in diameter) and marked elongation of the descending aorta along the vertebral bodies (Figure 2). Transthoracic echocardiography revealed a redundant tricuspid aortic valve with severe regurgitation. The left ventricular ejection fraction was $45 \%$, as estimated by ventriculography.

At the time of sternotomy, we paid particular attention to avoiding lung injury and to not opening the pleural spaces. After establishment of cardiopulmonary bypass, the aortic root was replaced with a composite graft by use of the Carrel patch technique because aortic leaflets were severely degenerated. Weaning from bypass was uneventful.

ABGs on admission to the intensive care unit were favorable: pH, 7.38; $\mathrm{PaCO}_{2}, 50.1 \mathrm{~mm} \mathrm{Hg} ; \mathrm{PaO}_{2}, 167.2 \mathrm{~mm} \mathrm{Hg}$; base excess, $4.4 \mathrm{mmol} / \mathrm{L}$ (synchronized intermittent mandatory ventilation; fraction of inspired oxygen of 0.5 ; respiratory rate of 12 breaths/ 


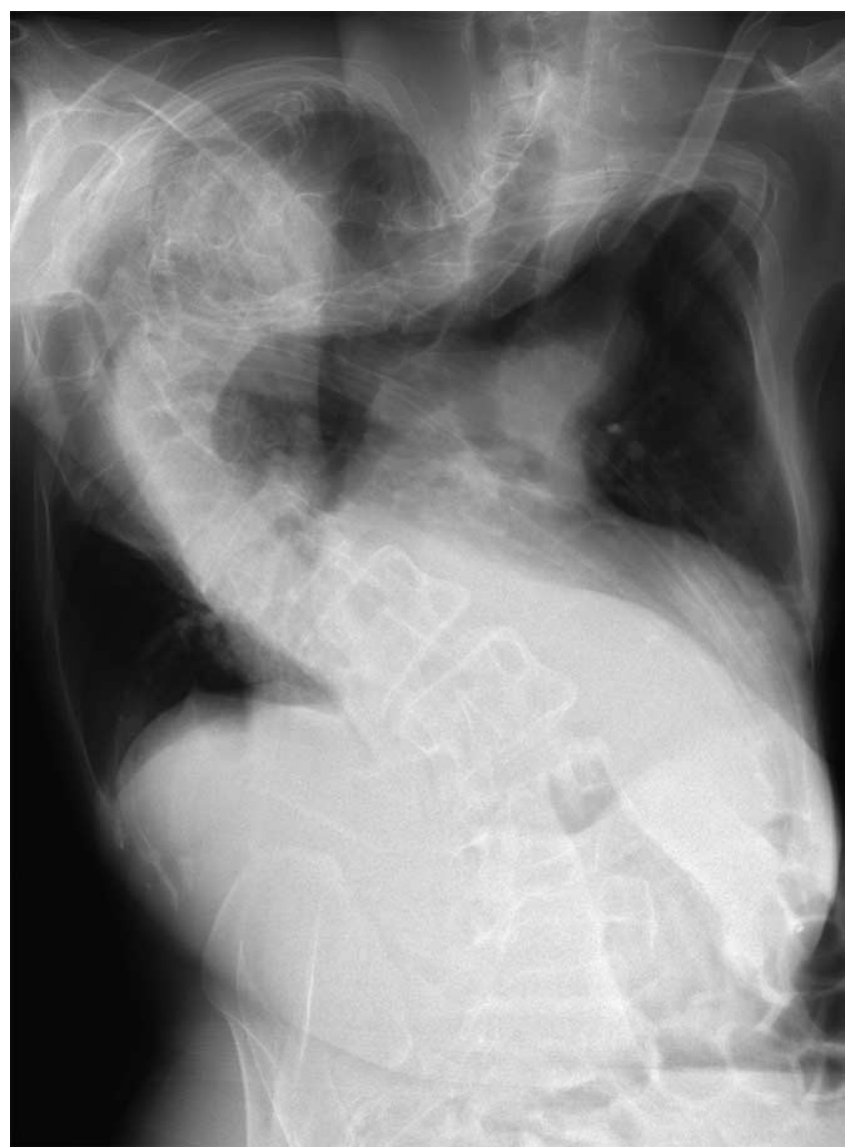

Figure 1. Chest radiograph shows cardiomegaly with mild lung congestion and severe scoliosis.

min; tidal volume of $460 \mathrm{~mL}$; positive end-expiratory pressure of $4 \mathrm{~cm} \mathrm{H}_{2} \mathrm{O}$ ). The trachea was extubated 4 hours after the admission, when he was completely alert and oriented. However, he had respiratory distress immediately after the extubation, and his respiratory rate exceeded 40 breaths/min. Subsequent ABGs with 10 $\mathrm{L}$ of oxygen showed respiratory acidosis: $\mathrm{pH}, 7.299 ; \mathrm{PaCO}_{2}, 57.1$ $\mathrm{mm} \mathrm{Hg} ; \mathrm{PaO}_{2}, 130.7 \mathrm{~mm} \mathrm{Hg}$; base excess, $1.4 \mathrm{mmol} / \mathrm{L}$. Therefore, we applied BiPAP ventilatory support (BiPAP vision, Respironics, Inc) through a face mask. The inspiratory and expiratory pressures were set at 10 and $4 \mathrm{~cm} \mathrm{H}_{2} \mathrm{O}$, respectively. The respiratory rate decreased to the mid-20s in beats per minute, and ABGs showed an improvement of acidemia: $\mathrm{pH}, 7.359 ; \mathrm{PaCO}_{2}, 52.3 \mathrm{~mm} \mathrm{Hg}$; $\mathrm{PaO}_{2}, 118.3 \mathrm{~mm} \mathrm{Hg}$; base excess, $3.1 \mathrm{mmol} / \mathrm{L}$. We could terminate BiPAP ventilation the next morning and resumed nasal continuous positive airway pressure ventilation for subsequent respiratory support. The patient was discharged from the hospital without any complications. Spirometry examined before discharge showed no remarkable change compared with the preoperative values.

\section{Discussion}

Pectus excavatum and scoliosis, commonly associated with Marfan syndrome, cause restrictive pulmonary dysfunction, al-

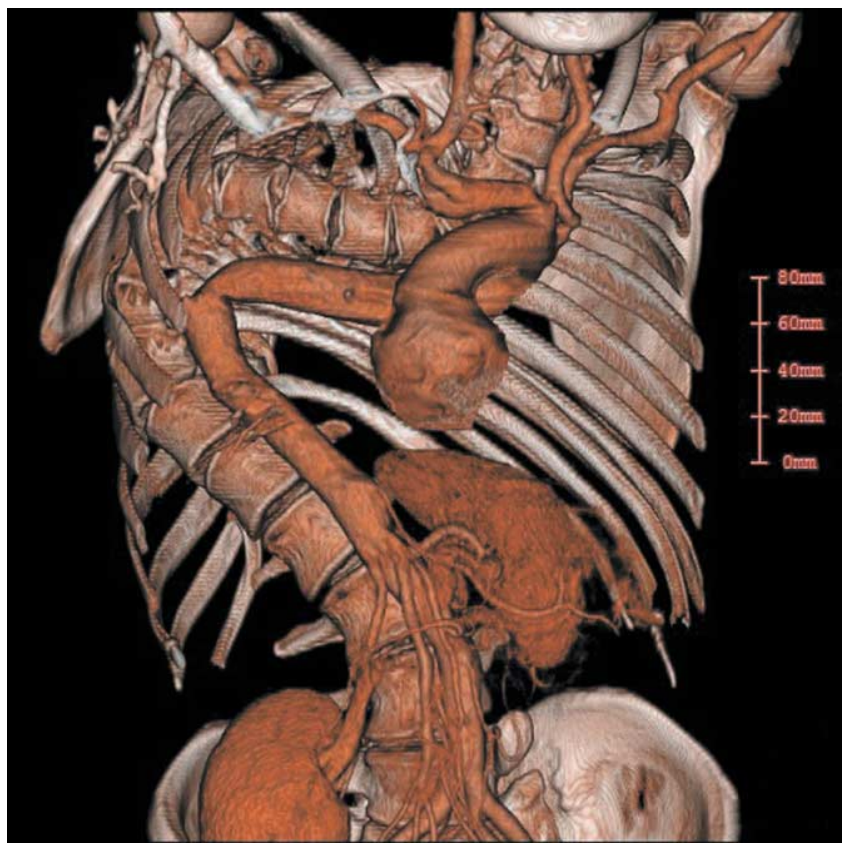

Figure 2. CT scan reveals dilatation of the aortic root $(62 \mathrm{~mm}$ in diameter) and marked elongation of the descending aorta along the vertebral bodies.

though the connective tissue defects in Marfan syndrome seem to have little clinical effect on such dysfunction. ${ }^{1}$ Accordingly, patients with severe chest deformities are still predisposed to a risk of respiratory deterioration, even after a successful extubation. Avoidance of reintubation is of great importance because mortality increases more than 7-fold with reintubation and subsequent mechanical ventilation. ${ }^{2}$

The BiPAP ventilator is one of relatively novel noninvasive ventilators and has gained increasingly widespread acceptance in acute and chronic respiratory failure. ${ }^{3}$ However, the rationale of BiPAP application after elective extubation is still controversial. Ferrer and colleagues ${ }^{4}$ reported that BiPAP facilitated weaning from mechanical ventilation, whereas Esteban and associates ${ }^{5}$ insisted BiPAP did not prevent reintubation in patients who had respiratory failure after extubation. The maximum feature of $\mathrm{Bi}$ PAP ventilation is the ability to provide ventilatory assistance noninvasively for alert and spontaneously breathing patients. It is expected that inspiratory pressure support augments ventilation, even in patients with decreased vital capacity, and positive endexpiratory pressure restores functional residual capacity. As a result, the work of breathing decreases. We believe decrease of respiratory rate was the clinical sign of reduced respiratory workload in the current patient.

In conclusion, we report a case of severe pulmonary dysfunction caused by chest deformity in a patient who tolerated aortic root replacement as a result of adequate respiratory management. Our experience should reassure patients with severe respiratory dysfunction necessitating cardiovascular surgery. 


\section{References}

1. Streeten EA, Murphy EA, Pyeritz RE. Pulmonary function in the Marfan syndrome. Chest. 1987;91:408-12.

2. Epstein SK, Ciubotaru RL, Wong JB. Effect of failed extubation on the outcome of mechanical ventilation. Chest. 1997;112:186-92.

3. Tokuda Y, Matsumoto M, Sugita T, et al. Bilateral diaphragmatic paralysis after aortic surgery with topical hypothermia: ventilatory assistance by means of nasal mask bilevel positive pressure. $J$ Thorac Cardiovasc Surg. 2003;125:1158-9.

4. Ferrer M, Esquinas A, Arancibia F, et al. Noninvasive ventilation during persistent weaning failure: a randomized controlled trial. Am J Respir Crit Care Med. 2003;168:70-6.

5. Esteban A, Frutos-Vivar F, Ferguson ND, et al. Noninvasive positivepressure ventilation for respiratory failure after extubation. $N$ Engl J Med. 2004;350:2452-60.

\title{
Embryologic and surgical considerations in tetralogy of Fallot with right arch and aberrant left subclavian artery from the ascending aorta
}

\author{
K. G. Shyam Krishnan, MCh, Sanjay Theodore, MS, Sai Kiran K. V. S. S., \\ MCh, and Kurur Sankaran Neelakandhan, MCh, Kerala, India
}

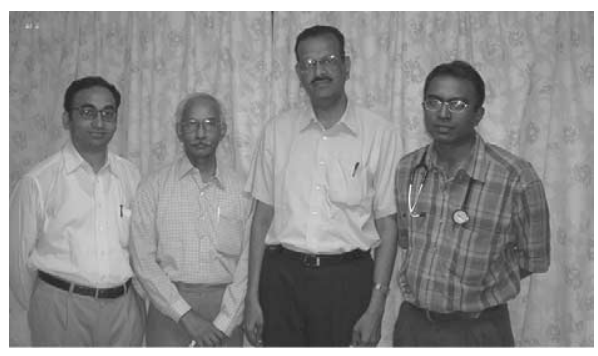

Left to right: Sai Kiran, Neelakandhan, Shyam Krishnan, Theodore
A nomalies of the right aortic arch are common in tetralogy of Fallot (TOF). Aberrant left subclavian artery (LSA) from the Kommerell diverticulum and isolation of the LSA are occasionally encountered. LSA arising as the first branch of a right aortic arch has been reported $^{1}$; however, this is the first report of aberrant LSA arising from the ascending aorta in TOF with a right aortic arch.

\section{Clinical Summaries}

PATIENT 1. A 12-year-old boy had a history of cyanosis since 3 months of age. TOF was diagnosed when he was 3 months old, and he was lost to follow-up. On examination all peripheral pulses were palpable, and blood pressure was $110 / 70 \mathrm{~mm} \mathrm{Hg}$ in both the upper limbs. Both heart sounds were heard, and there was a grade $3 / 6$ ejection systolic murmur over the second left intercostal space. Preoperative blood chemistry, hematology, and coagulation profile showed normal results. Chest radiography and electrocardiogram were consistent with TOF. Transthoracic echocardiography showed a right aortic arch, large subaortic ventricular septal defect with aorta-mitral continuity, and severe infundibular hypertrophy. The pulmonary annulus was small, and the branch pulmonary

From the Department of Cardiovascular and Thoracic Surgery, Sree Chitra Tirunal Institute for Medical Sciences and Technology, Trivandrum, Kerala, India.

Received for publication Oct 20, 2004; accepted for publication Nov 1, 2004.

Address for reprints: Professor Shyam Krishnan KG, Department of Cardiovascular and Thoracic Surgery, Sree Chitra Tirunal Institute for Medical Sciences and Technology, Trivandrum, Kerala, India 695011.

J Thorac Cardiovasc Surg 2005;130:215-6

$0022-5223 / \$ 30.00$

Copyright $\odot 2005$ by The American Association for Thoracic Surgery

doi:10.1016/j.jtcvs.2004.11.004 arteries were of a good size. At surgery an abnormal LSA arising from the ascending aorta anterolaterally was found, coursing anterior to the trachea and the esophagus. This vessel was looped and snugged before delivery of cardioplegic solution. The patient had an uneventful postoperative course and is on regular follow-up.

PATIENT 2. TOF was diagnosed at the age of 3 months in patient 2 when the parents noticed cyanosis. The patient's heart rate was 130 beats/min and blood pressure was $90 / 60 \mathrm{~mm} \mathrm{Hg}$ in both the upper limbs. Chest radiograph and electrocardiogram were consistent with TOF. Transthoracic echocardiography showed a right aortic arch, a large subaortic ventricular septal defect with a 50\% aortic override, a hypertrophied right ventricle, and confluent and adequate-sized pulmonary arteries. Coronary anatomy was not well defined, so a cardiac catheterization and angiography were performed. The ascending aortic angiogram showed an aberrant LSA arising from the posterolateral ascending aorta and passing anterior to the trachea and esophagus (Figure 1). The patient underwent successful corrective surgery. During surgery, the aortic clamp was applied proximal to the aberrant vessel.

\section{Discussion}

A right aortic arch occurs in approximately $25 \%$ of patients with TOF with pulmonary stenosis. The right arch shows 3 branching patterns: mirror image branching, aberrant LSA, and the rare isolation of the LSA. The aberrant subclavian artery arises from the descending aorta. To date there are no reports in the English literature describing the origin of the LSA from the ascending aorta in TOF with right aortic arch. ${ }^{1}$

The branching configuration of the right aortic arch largely depends on the pattern of left arch regression. In the commonly found mirror image branching, the distal portion of the left arch regresses, the proximal portion incorporates with the subclavian artery, and the innominate forms on the left. The aberrant LSA is formed from the left dorsal aorta, left fourth arch, and left seventh intersegmental artery. ${ }^{2}$ 